\title{
APROVECHAMIENTO DE AGUAS RESIDUALES DOMÉSTICAS PARA PRODUCCIÓN DE BIOGÁS Y BIOL MEDIANTE DIGESTORES DE CARGA DIARIA
}

\author{
USE OF DOMESTIC WASTEWATER FOR THE PRODUCTION OF BIOGAS AND ORGANIC \\ FERTILIZER USING ANAEROBIC REACTORS OF DAILY SUPPLY
}

\author{
${ }^{1}$ Lucila Pinto C. y ${ }^{2}$ Lawrence Quipuzco U.
}

\begin{abstract}
Resumen
Esta investigación surge como una alternativa para la reutilización de las aguas residuales domésticas, en específico de las aguas amarillas (orines) y grises (aguas de lavado) como fuente de alimentación de biodigestores, y de esta manera encontrar un sustituto al agua de uso cotidiano que se necesita para el correcto funcionamiento de los mismos. Los objetivos de la investigación fueron evaluar la calidad y cantidad de biogás, la calidad del biol y la reducción de patógenos en biodigestores tipo semi continuo para dos tratamientos. Para los dos tratamientos se usó el mismo sustrato base, que fue purín de cerdo, la variación entre los dos tratamientos consistió en el agua a utilizar: el Tratamiento 1 estuvo alimentado con aguas residuales y el Tratamiento 2 con agua de pozo. Para la composición de biogás se obtuvo un promedio de $\mathrm{CH}_{4}$ de 50,6\% para el Tratamiento 1, alimentado con aguas residuales y un promedio de $48.6 \%$ para el Tratamiento 2, alimentado con agua de pozo. La mayor producción de biogás la obtuvo el Tratamiento 1 (85.19 Litros/Kg.ST), en comparación con el Tratamiento 2 (69.8 Litros/Kg ST) con un tiempo de retención de 30 días en los dos tratamientos. El biol producido en los dos tratamientos presenta micronutrientes: nitrógeno, fósforo y potasio en su composición. La calidad del biol para el tratamiento con aguas residuales presenta concentraciones mayores de macronutrientes que el biol obtenido con el tratamiento de agua de pozo. Los coliformes totales se redujeron para los dos tratamiento de 4 a 3 unidades logarítmicas, alcanzándose una reducción del $90 \%$ de patógenos. Para los coliformes fecales se tuvo una reducción de 2 a 1 unidad logarítmica lográndose también una reducción del $90 \%$ de patógenos.
\end{abstract}

Palabras claves: Aguas grises, aguas amarillas, biodigestor, biogás, biol.

\begin{abstract}
This research study approaches as a solution for the reuse of domestic wastewater, specifically of yellow water (urines) and grey water (laundry, dishwashing, and bathing wastewater) as liquid supply for anaerobic reactors, and in this way to find a substitute to the daily use water, which is used as supply for the reactors, which need water for their right development. The goals of the research were comparing between the treatments the quality and volume of biogas, quality of organic fertilizer and pathogen control using semi continuous anaerobic reactors for two treatments. For both treatments used the same basic substratum, which was pig manure, the difference between the two treatments was the quality of water that we use. For Treatment 1 , it used domestic wastewater as supply, for Treatment 2 , is used well water extracted of university tank. For biogas quality, Treatment 1 reached an average concentration of $50.6 \%$ of methane, and for Treatment 2, an average concentration of $48.6 \%$. For biogas volume, Treatment 1 obtained a production of 69.8 Liters $/ \mathrm{Kg}$.ST and Treatment 2 obtained a production of $69.8 \mathrm{Liters} / \mathrm{Kg}$ ST. Both treatments had a retention time of 30 days. The organic fertilizers produced in the two treatments present micronutrients nitrogen, phosphorus and potassium in composition. The organic fertilizers quality for wastewater treatment show higher concentrations of macronutrients than biol from treatment of well water. Anaerobic digestion reduced the concentration of fecal coliforms bacteria from 3 to 2 logarithmic units in both treatments. For total coliform bacteria, it had a reduction of 1 logarithmic unit from 3 to 2 . The concentrations of fecal coliform bacteria are below the maximum allowable limits for irrigation water established in the Peruvian Standards.
\end{abstract}

Key words: Anaerobic digestion, anaerobic reactor, biogas, domestic waste water, organic fertilizer.

\section{Introducción}

La alimentación que se realiza a un biodigestor es la mezcla de una fase sólida; que viene a ser el sustrato a degradar mediante la digestión anaeróbica, que es en la mayoría de los casos estiércol de animales; y de una fase líquida donde normalmente se emplea agua de uso cotidiano, sin embargo, según la disponibilidad del 
recurso, éste puede ser sustituido, en parte, por otros líquidos como el suero de leche (Martí, 2008).

Según Martí (2008) para alimentar diariamente un biodigestor de tipo tubular de ocho metros cúbicos se necesitaría sesenta litros de agua por cada veinte kilos de estiércol de vacuno, considerando tiempos de retención prolongados, alrededor de sesenta o setenta días, en consecuencia hay un alto consumo del recurso agua, lo que puede afectar a una familia que no tenga acceso continuo al agua o el acceder a ella tenga un costo elevado. Ante este problema se necesita encontrar un sustituto líquido para el volumen de agua que es requerido para el correcto funcionamiento de un biodigestor.

El objetivo principal de este estudio es evaluar la reutilización de aguas residuales domesticas para la producción de biogás y fertilizante orgánico mediante biodigestores de carga diaria, utilizando como indicadores: la calidad de biogás, la producción de biogás, la calidad del fertilizante orgánico resultante y la disminución de la concentración de patógenos.

\section{Materiales y métodos}

Este estudio fue realizado en el Laboratorio de Ingeniería Ambiental de la Universidad Nacional Agraria la Molina (UNALM), entre los meses de enero y agosto del 2012.

El diseño experimental fue un DCA (Diseño Completamente al Azar) con dos tratamientos y tres repeticiones. Los tratamientos fueron los siguientes:

Tratamiento 1: Purín de cerdo + agua residual (aguas amarillas y aguas grises obtenidas de los servicios higiénicos de varones de primer piso del Laboratorio de Ingeniería Ambiental).

Tratamiento 2: Purín de cerdo + agua de pozo (obtenida del agua de los grifos del Laboratorio de Ingeniería Ambiental, proveniente del pozo de la UNALM)

Los dos tratamientos contenían purín de cerdo obtenido del Programa de Cerdos de la UNALM, como sustrato base. Asimismo se planteó el experimento en tres etapas para poder observar la evolución del sistema: la carga inicial, la carga diaria y el periodo control.

Para el ensayo se diseñó un biodigestor del tipo semi continuo de 64 litros de volumen líquido cargado con $8 \%$ de sólidos totales.

En la Figura 1 se puede observar el diseño del biodigestor utilizado en la investigación.

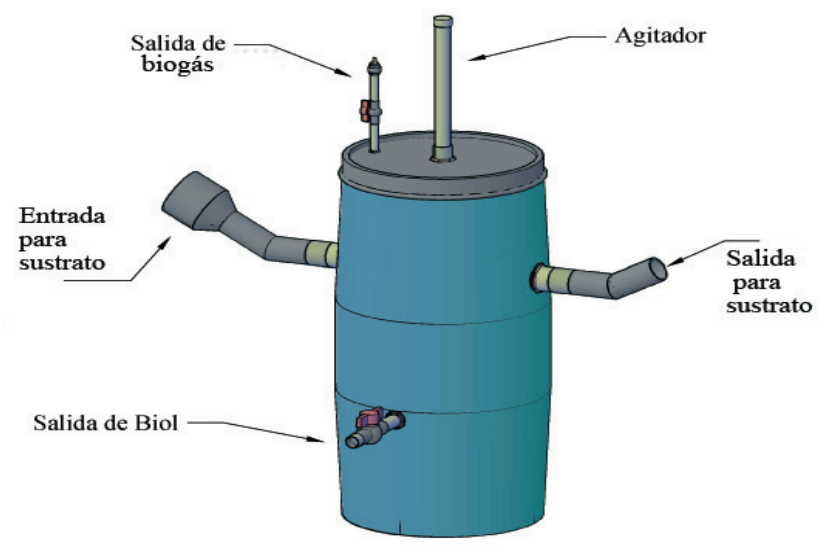

Figura 1. Diseño del reactor biodigestor.

Se realizó la caracterización de las aguas residuales (amarillas y grises). Se calculó la producción diaria de las aguas residuales, así como una caracterización físicoquímica de los principales parámetros que nos permitieron tener información de la calidad del agua. Los parámetros analizados fueron: temperatura, $\mathrm{pH}$, conductividad eléctrica, oxígeno disuelto, turbiedad, sólidos totales y volátiles, demanda bioquímica de oxígeno $\left(\mathrm{DBO}_{5}\right)$, demanda química de oxígeno (DQO), alcalinidad, fósforo total, nitrógeno, sulfatos, detergente, coliformes totales y coliformes fecales. Asimismo se realizó un análisis del agua de pozo que se iba a utilizar para el segundo tratamiento, analizándose los siguientes parámetros: $\mathrm{pH}$, temperatura, nitrógeno, conductividad, sólidos totales y sólidos volátiles. Se seleccionó esos parámetros por la influencia que éstas tendrían sobre la calidad del biogás y biol. En la Figura 2 se puede observar la recolección de muestras de agua residual para el posterior análisis.

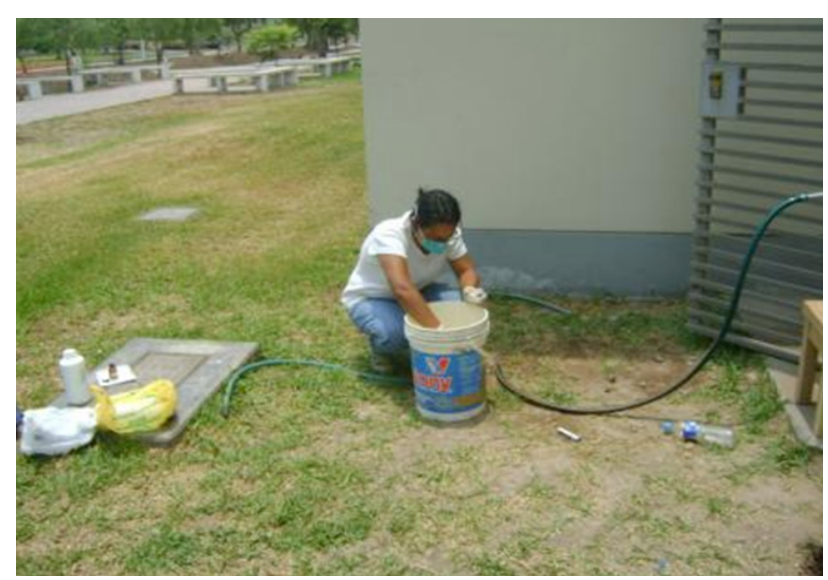

Figura 2. Recolección de muestras de agua residual.

Además se realizó un análisis de la humedad contenida en el purín de cerdo para determinar la cantidad que se iba a utilizar en cada uno de los tratamientos. Luego de calcular la cantidad de sustrato que se iba a utilizar en la carga inicial, se calculó la cantidad de sustrato a utilizar en la carga diaria, tomando en cuenta el tiempo de retención, 
que para el presente experimento corresponde a 30 días considerando una temperatura ambiental promedio de $20^{\circ} \mathrm{C}$.

Para la carga incial, se procedió a llenar un cilindro de 220 litros de capacidad con las cantidades calculadas de agua de pozo y purín de cerdo y se procedió a cargar cada biodigestor correspondiente al Tratamiento 2, luego se volvió a llenar el cilindro con purín de cerdo y agua residual proveniente del bidón de almacenamiento mediante bombeo y se procedió a llenar los biodigestores restantes correspondientes al Tratamiento 1. Una vez realizado el sellado de los reactores, se procedió a conectar los gasómetros a los reactores para el almacenamiento de biogas producido. Al cabo de los 30 días cuando se observó una concentración estable de metano en el gas producido, se llevó a cabo la segunda fase de la parte experimental. La carga diaria de los reactores se dio durante un mes, el cual corresponde al tiempo de retención calculado en base a la temperatura ambiental. En la Figura 3 se puede observar la carga de uno de los biodigestores.

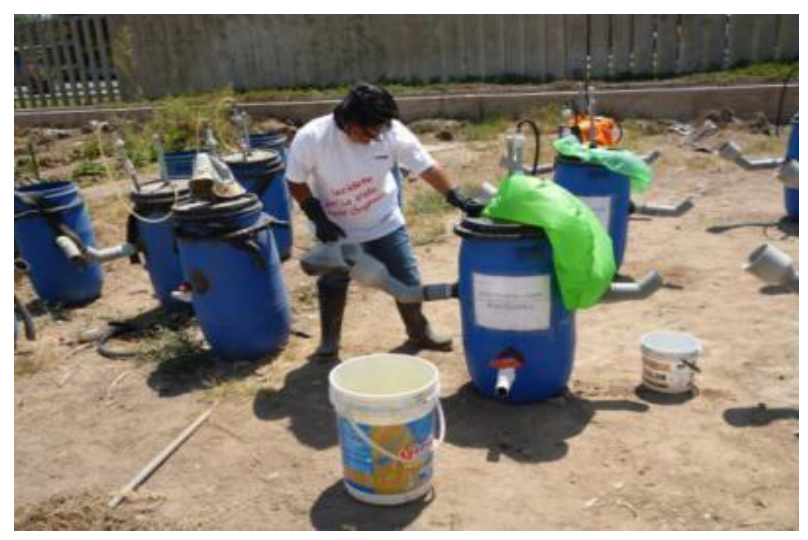

Figura 3. Carga diaria a los biodigestores.

Durante la etapa de operación de los biodigestores se tomaron en cuenta en el levantamiento de datos y toma de muestras los siguientes parámetros:

\section{pH}

Para realizar la medición del pH se utilizó un potenciómetro de campo del Laboratorio de Ingeniería Ambiental. La medición se realizó dos veces por semana por espacio de 14 semanas.

\section{Composición del biogás}

Para medir la composición del biogás se utilizó el equipo Monitor de Gas por Extracción, marca LANTEC, modelo GEM500, el cual nos muestra la composición porcentual de $\mathrm{CH}_{4}, \mathrm{CO}_{2}, \mathrm{O}_{2}$ y gases trazas en el biogás. Las mediciones se realizaron dos veces por semanas en un lapso de 14 semanas que duró la fase experimental. Se tomó como intervalo realizar las mediciones dos veces por semana para dejar un intervalo de tiempo para ver la evolución de la concentración de gases en el biogás.

\section{Temperatura}

La temperatura interna en los biodigestores se midió con el equipo de Gas por Extracción, marca LANTEC, modelo GEM500, el cual tiene un sensor de temperatura. Las mediciones se realizaron dos veces por semanas durante un lapso de 14 semanas. Los datos de temperatura ambiental se obtuvieron de la UNALM, a través del observatorio Alexander Von Humboldt.

\section{Volumen de biogás}

Para la medición del volumen de biogás producido se adaptó un sistema de medición basado en desplazamiento de volúmenes. Se adaptó un bidón para agua de 20 litros de capacidad con mangueras que permitían el ingreso del gas contenido en los gasómetros hacia el bidón que contenía agua, lo que por diferencia de presiones, hacía que el agua se desplazara hacia una jarra graduada donde se podía medir el volumen de agua equivalente al gas contenido en el gasómetro. La medición de volumen se realizó una vez por semana.

\section{Análisis microbiológico}

Los análisis microbiológicos que se realizaron fueron los de coliformes totales y coliformes fecales, los cuales se analizaron dos veces durante la evaluación. La primera medición se realizó el día que se hizo la carga inicial y la segunda medición se realizó al final de la semana 14 de la parte experimental.

\section{Biol}

Para determinar la calidad de biol se realizaron análisis de macronutrientes. El análisis se realizó en el Laboratorio de Análisis de Suelos, Plantas, Aguas y Fertilizantes de la UNALM. Las muestras de biol fueron colectadas al final de la semana 14 de la parte experimental.

Para la validación estadística de los datos se utilizó el programa Minitab 16, utilizándo el coeficiente de variabilidad, análisis de varianza y la prueba de Tukey, la cual permitió evaluar la significancia de todas las diferencias entre tratamientos. Para el análisis de varianza (ANVA) y la pruba de Tukey se tomó un nivel de significancia del 5\%.

\section{Resultados y discusión}

Los resultados para la caracterización del agua residual se muestran en la Tabla 1. La caracterización de ciertos parámetros se realizó dos veces a lo largo de todo el proceso para evaluar como varía la calidad del agua en el tiempo. La primera evaluación se realizó en el mes de febrero del año 2012, antes de realizar la carga inicial en el reactor. La segunda evaluación se realizó en el mes de mayo del año 2012, durante el periodo control del experimento. 
Tabla 1. Resultados de parámetros medidos para aguas residuales provenientes del Laboratorio de Ingeniería Ambiental.

\begin{tabular}{|c|c|c|c|}
\hline Parámetro & Unidades & Valor 1 & Valor 2 \\
\hline Temperatura & ${ }^{\circ} \mathrm{C}$ & 22.5 & 20.5 \\
\hline $\mathrm{pH}$ & - & 8.79 & 8.01 \\
\hline $\begin{array}{l}\text { Conductividad } \\
\text { eléctrica }\end{array}$ & $\mu \mathrm{s} / \mathrm{cm}$ & 6540 & - \\
\hline Oxigeno disuelto & $\mathrm{mg} / \mathrm{l}$ & 0.40 & - \\
\hline Turbiedad & UNT & 162 & - \\
\hline Sólidos totales (ST) & $\mathrm{mg} / \mathrm{l}$ & 3128.0 & 4152.0 \\
\hline Sólidos volátiles (SV) & $\mathrm{mg} / \mathrm{l}$ & 960.0 & 1688.0 \\
\hline $\begin{array}{l}\text { Demando bioquímica } \\
\text { de oxígeno }\left(\mathrm{DBO}_{5}\right)\end{array}$ & $\mathrm{mg} / \mathrm{l}$ & 390 & - \\
\hline $\begin{array}{l}\text { Demanda química de } \\
\text { oxigeno (DQO) }\end{array}$ & $\mathrm{mg} / \mathrm{l}$ & 1200 & - \\
\hline Alcalinidad & $\mathrm{mg} / \mathrm{l}$ & 820.0 & - \\
\hline Fosforo total (P) & $\mathrm{mg} / \mathrm{l}$ & 18.18 & - \\
\hline Nitrógeno $(\mathrm{N})$ & $\%$ & 0.04 & 0.08 \\
\hline Sulfatos $\left(\mathrm{SO}_{4}\right)$ & $\mathrm{mg} / \mathrm{l}$ & 1854.24 & - \\
\hline Detergentes & $\mathrm{mg} / \mathrm{l}$ & 0.42 & - \\
\hline Coliformes totales & $\mathrm{NMP} / 100 \mathrm{ml}$ & 350 & - \\
\hline Coliformes fecales & $\mathrm{NMP} / 100 \mathrm{ml}$ & $<1.8$ & - \\
\hline
\end{tabular}

Se observa que para la temperatura se tiene promedio mayor a los $20^{\circ} \mathrm{C}$. En promedio se presentó un valor de $\mathrm{pH}$ de 8.4 , por lo que se puede decir que las aguas residuales son alcalinas. Se justifica este elevado $\mathrm{pH}$ debido a la fuente de alcalinidad que tenía el medio y que corresponde a $820 \mathrm{mg} \mathrm{CaCO}_{3} / 1$.

Se tiene un valor de conductividad eléctrica que corresponde a $6540 \mathrm{uS} / \mathrm{cm}$, teniendo como fuente principal de conductividad a los sulfatos con un valor de $1854.24 \mathrm{mg} / \mathrm{l}$.

Con respecto al oxígeno disuelto se tiene un valor bajo, característico de las aguas residuales, que corresponde a $0.40 \mathrm{mg} / \mathrm{l}$. Para la turbiedad se tiene un valor no muy alto, correspondiente a 162 UNT. Para el caso del $\mathrm{DBO}_{5}$ y DQO, la relación entre $\mathrm{DBO}_{5}$ y DQO es de 0.32 lo que indica la biodegradabilidad de las mismas. Se encontró un valor de fósforo total de $18.18 \mathrm{mg} / \mathrm{l} \mathrm{y}$ un valor promedio de nitrógeno total de $0.06 \%$.

Se obtuvo una concentración de detergentes de $0.42 \mathrm{mg} / 1$ que está muy por debajo de la concentración inhibidora de metanogénesis de 20 a $40 \mathrm{mg} / 1$.

Respecto a la carga patógena se tiene un valor de coliformes totales de $350 \mathrm{NMP} / 100 \mathrm{ml}$ y un valor de coliformes fecales menor a $1.8 \mathrm{NMP} / 100 \mathrm{ml}$.

En la Tabla 2 se tienen los resultados correspondientes a la caracterización del agua de pozo.

$\mathrm{Al}$ igual que para las aguas residuales la temperatura fue cercana a $20.1^{\circ} \mathrm{C}$. Se tiene un $\mathrm{pH}$ ligeramente alcalino correspondiente a 7.5, esto se debe a que el agua de pozo de la UNALM es un agua con un alto contenido en sales, tal como lo evidencia el valor de conductividad eléctrica.

En la Figura 4 se observa el comportamiento de la temperatura a lo largo de todo el proceso. Se nota una tendencia de disminución de la temperatura ambiental conforme avanza el tiempo, debido a la cercanía de la estación de invierno. El experimento se inició finales del mes de febrero hasta inicios del mes de junio del año 2012.

Tabla 2. Resultados de parámetros para agua de pozo Fecha: 02/2012.

\begin{tabular}{lcc}
\hline \multicolumn{1}{c}{ Parámetro } & Unidades & Valor \\
\hline Temperatura & ${ }^{\circ} \mathrm{C}$ & 20.1 \\
$\mathrm{pH}$ & - & 7.5 \\
Conductividad eléctrica & $\mathrm{uS} / \mathrm{cm}$ & 3170 \\
Sólidos totales $(\mathrm{ST})$ & $\mathrm{mg} / \mathrm{l}$ & 2932.0 \\
Sólidos volátiles $(\mathrm{SV})$ & $\mathrm{mg} / \mathrm{l}$ & 1100.0 \\
Nitrógeno $(\mathrm{N})$ & $\%$ & 0.00 \\
\hline
\end{tabular}

El promedio de la temperatura interna de los reactores fue de $31.8^{\circ} \mathrm{C}$, con la presencia de microorganismos que trabajan en el rango mesofílico $\left(25-45^{\circ} \mathrm{C}\right)$. Realizando una comparación entre los dos tratamiento se puede apreciar en promedio que la temperatura para el Tratamiento $1\left(32.2^{\circ} \mathrm{C}\right)$ ha sido mayor que para el Tratamiento 2 $\left(31.3^{\circ} \mathrm{C}\right)$. Comparando estos datos con la temperatura ambiental, la cual fue en promedio de $25^{\circ} \mathrm{C}$ durante la fase experimental, se observa que la temperatura interna fue mayor en $6^{\circ} \mathrm{C}$ que la temperatura ambiental, lo que nos indica que en el proceso de biodigestión el metabolismo de las bacterias y el crecimiento bacteriano aumenta la temperatura interna del reactor.

En la Figura 5 se puede apreciar el comportamiento del $\mathrm{pH}$. Se observa que los valores obtenidos se encuentran en un rango no muy amplio, con un valor mínimo de 7.10 y con un valor máximo de 7.47. Estos valores se encuentran en el rango apropiado para que se desarrolle la actividad metanogénica que va de 6.5 a 8 (Martí, 2006), teniéndose como rango ideal de 6.8 a 7.2.

Se observa que siempre se tienen mayores valores de $\mathrm{pH}$ en el Tratamiento 1, es ahí donde se ve la influencia del $\mathrm{pH}$ de las aguas residuales, que es alcalino. Caso contrario ocurre con el Tratamiento 2, a pesar de que el agua de pozo también tiene un $\mathrm{pH}$ alcalino, alrededor de 7.5, siempre nos da valores menores a los del agua residual.

Se puede apreciar cómo se inicia el proceso con un $\mathrm{pH}$ alto y conforme van pasando los días comienza a disminuir hasta estabilizarse en un rango de 7.15 - 7.30 alrededor de la semana 4 donde se empieza a realizar la carga diaria y se mantiene en se rango hasta aproximadamente la semana 8 donde se termina de realizar la carga diaria

En la Figura 6 se puede apreciar como fue el comportamiento del metano dentro de la composición del biogás durante toda la fase experimental. Se observa que se tiene una producción de metano desde la primera semana y que conforme pasa las semanas va aumentando la concentración del mismo. Para los dos tratamientos se 
observa que en las cuatro primeras semanas se tiene un aumento exponencial de la concentración de metano en el biogás, esto se debe a la gran cantidad de materia fresca en el biodigestor.

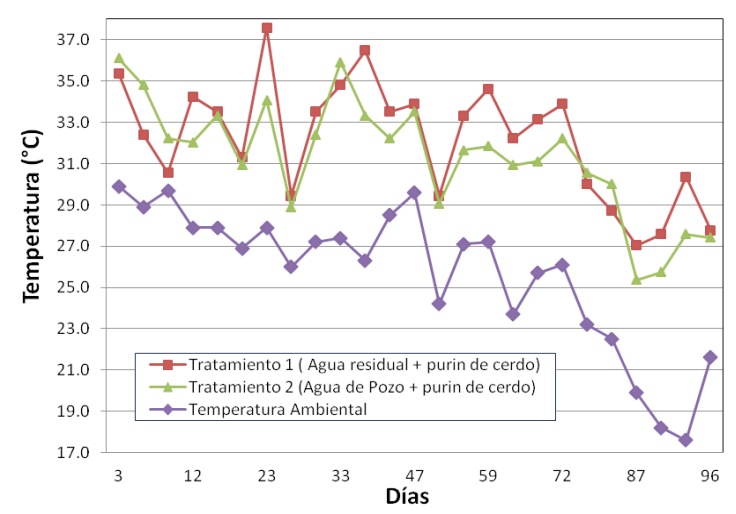

Figura 4. Comportamiento de la temperatura interna y ambiental en los tratamientos.

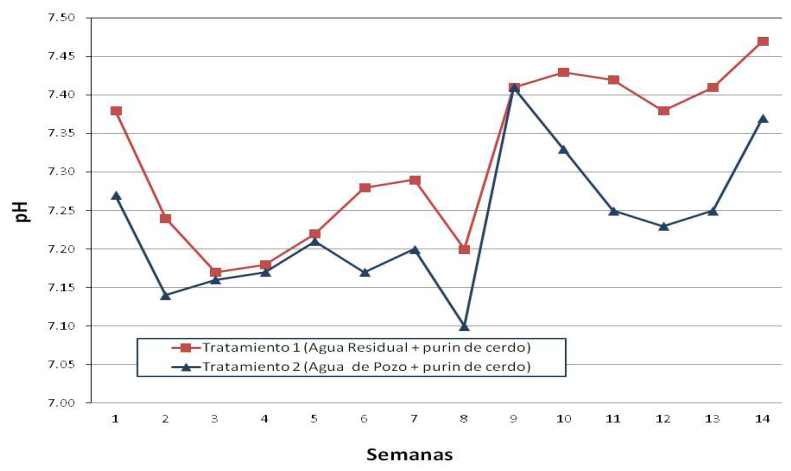

Figura 5. Comportamiento del $\mathrm{pH}$ durante el experimento.

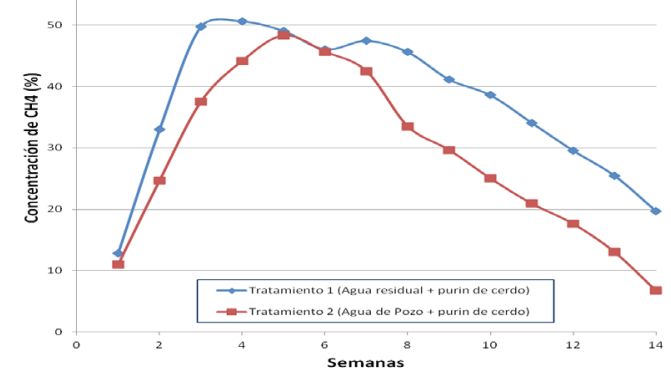

Figura 6. Comportamiento porcentual del metano en la fase experimental.

Al realizarse la carga diaria, para el caso del Tratamiento 1 la concentración de metano disminuye y vuelve a subir manteniéndose constante durante todo el periodo de alimentación que fue de 4 semanas. Para el caso de Tratamiento 2 se observa que cuando se realiza la alimentación, la concentración de metano va disminuyendo. Esto se debe a que la materia orgánica contenida en la alimentación diaria no es suficiente para que se mantenga la actividad metanogénica constante. En el Tratamiento 1 se mantiene constante debido al aporte de materia orgánica que generan las aguas residuales.

Cuando se deja de cargar el sistema se observa la disminución de la concentración de metano en el tiempo, y esto se debe a que ya no se tiene materia orgánica fresca que se pueda degradar.

Al realizar el ANVA correspondiente a los datos obtenidos, se obtienen los siguientes resultados:

Tabla 3. Análisis de Varianza (ANVA) para composición de biogás .

\begin{tabular}{lccccc}
$\begin{array}{l}\text { Fuentes de } \\
\text { Variación }\end{array}$ & $\begin{array}{c}\text { Grados de } \\
\text { Libertad }\end{array}$ & $\begin{array}{c}\text { Sumas de } \\
\text { Cuadrados }\end{array}$ & $\begin{array}{c}\text { Cuadrados } \\
\text { Medios }\end{array}$ & Fc & Ft $(1,26)$ \\
\hline Tratamientos & 1 & 530.598779 & 530.598779 & 3.16 & 4.23 \\
Error & 26 & 4354.9718 & 167.4989139 & & \\
Experimental & 27 & 4885.57054 & & & \\
Total & 27 & & & & \\
\hline
\end{tabular}

De la tabla anterior se obtiene que el Fc es menor que el Ft, entonces se puede concluir que los resultados obtenidos en la composición del biogás presenta homogeneidad por lo tanto no existe diferencia significativa entre el Tratamiento 1 y Tratamiento 2 .

En la Figura 7 podemos apreciar como fue la producción de biogás a lo largo de todo el proceso y se observa que la mayor producción de biogás se aprecia en la semana 6, es decir a la mitad del proceso y dentro del tiempo de retención calculado. Es ahí donde la actividad metanogénica se encuentra en su máximo grado y se mantiene constante debido a la carga diaria que se realiza. El pico de producción de biogás se produjo en la semana 7, disminuyendo la producción hacia las últimas semanas donde ya no se realizaba la carga diaria.

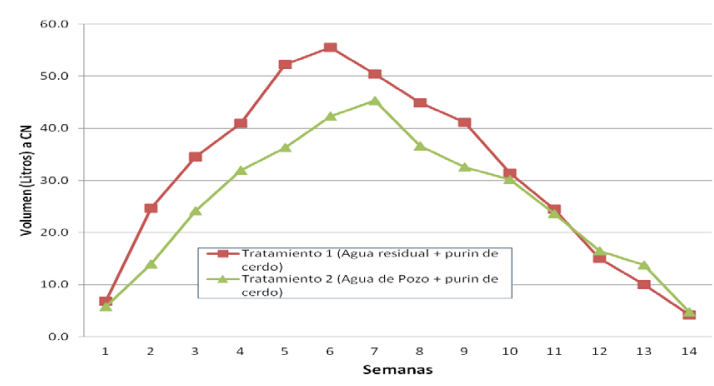

Figura 7. Producción de biogás en la fase experimental.

El Tratamiento 1 produjo un mayor volumen en comparación con el Tratamiento 2. Esto se debe a la cantidad de sólidos volátiles contenidos en cada uno de los tratamientos. Debido al agua residual, el Tratamiento 1 presenta una mayor cantidad de sólidos volátiles, luego transformados en biogás.

Al realizar el ANVA respectivo a los resultados obtenidos, se llegó a lo siguiente: 
Tabla 4. Análisis de Varianza (ANVA) para volumen producido de biogás

\begin{tabular}{|c|c|c|c|c|c|}
\hline Fuentes de Variación & Grados de Libertad & Sumas de Cuadrados & Cuadrados Medios & $\mathrm{Fc}$ & $\mathrm{Ft}(1,26)$ \\
\hline Tratamientos & 1 & 275.315714 & 275.315714 & 0.91 & 4.23 \\
\hline $\begin{array}{l}\text { Error Experimental } \\
\text { Total }\end{array}$ & $\begin{array}{l}26 \\
27\end{array}$ & $\begin{array}{r}7794.9490 \\
8070.26476 \\
\end{array}$ & 299.8057325 & & \\
\hline
\end{tabular}

De la tabla anterior se tiene que el Fc es menor al Ft, por lo que se tiene que los resultados obtenidos son homogéneos y no existe diferencia significativa entre los resultados obtenidos de Tratamiento 1 y Tratamiento 2 .

En la Figura 8, se puede apreciar el volumen acumulado de biogás producido para los dos tratamientos, siendo mayor el producido por el Tratamiento 1. Para el tratamiento con agua residual se tienen un volumen acumulado de 436.2 litros, y para el tratamiento con agua de pozo un volumen de 357.5 litros.

En la Tabla 5 se puede apreciar la producción de biogás expresados en Litros/kg ST.

En la Tabla 6 se pueden apreciar los resultados obtenidos del biol analizado. Se tiene que el pH para el Tratamiento 1 es mayor que para el Tratamiento 2, debido a que el $\mathrm{pH}$ del agua residual es mayor al $\mathrm{pH}$ del agua de pozo.

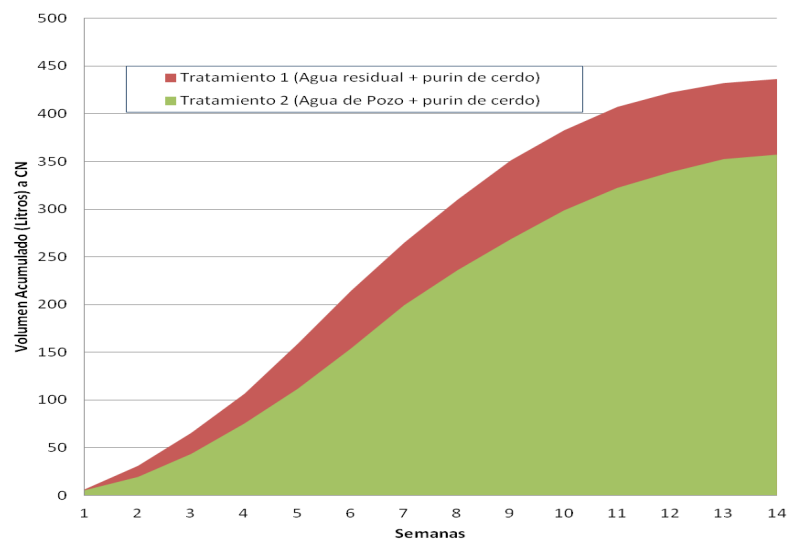

Figura 8. Volumen acumulado de biogás

Tabla 5. Producción de biogás expresado en Litros/kg ST.

\begin{tabular}{cccc}
\hline Tratamiento & $\begin{array}{c}\text { Volumen Acumulado } \\
\text { (Litros) }\end{array}$ & $\begin{array}{c}\text { Sólidos totales contenidos en } \\
\text { el purín }(\mathrm{Kg})\end{array}$ & $\begin{array}{c}\text { Producción } \\
\text { (Litros/kg ST) }\end{array}$ \\
\hline Tratamiento 1 & 436.2 & 5.12 & 85.19 \\
Tratamiento 2 & 357.5 & 5.12 & 69.8 \\
\hline
\end{tabular}

Tabla 6. Resultados de los análisis realizados al biol obtenido.

\begin{tabular}{|c|c|c|c|c|}
\hline Parámetros & Unidad & $\begin{array}{c}\text { Tratamiento } 1 \\
\text { (Purín de cerdo + agua residual) }\end{array}$ & $\begin{array}{c}\text { Tratamiento } 2 \\
\text { (Purín de cerdo + agua de pozo) } \\
\end{array}$ & $\begin{array}{c}\text { Biol de Agricultura Casa } \\
\text { Blanca } \\
\end{array}$ \\
\hline pH & - & 7.28 & 7.11 & 7.8 \\
\hline Sólidos totales & $\mathrm{g} / 1$ & 12.37 & 9.83 & - \\
\hline Materia orgánica & $\mathrm{g} / \mathrm{l}$ & 7.1 & 5.46 & 4.7 \\
\hline $\mathbf{N}$ total & $\mathrm{mg} / \mathrm{l}$ & 991.2 & 621.6 & 920.0 \\
\hline P total & $\mathrm{mg} / \mathrm{l}$ & 221.96 & 166.62 & 92.2 \\
\hline K total & $\mathrm{mg} / \mathrm{l}$ & 217.93 & 136.4 & 92.2 \\
\hline Ca total & $\mathrm{mg} / \mathrm{l}$ & 696 & 826.73 & 230.6 \\
\hline Mg total & $\mathrm{mg} / \mathrm{l}$ & 95.3 & 82.7 & 151.2 \\
\hline
\end{tabular}

En el caso de materia orgánica presente en el biol se observa que se tiene un mayor valor en el biol del Tratamiento 1 (7.1 g/l), en comparación con el obtenido del Tratamiento $2(5.46 \mathrm{~g} / \mathrm{l})$. La materia orgánica en el biol representa la cantidad de nutrientes que al ser mineralizados en el suelo van a dar aportes de nutrientes al mismo.

Para el caso del nitrógeno total se observa una diferencia considerable de concentración entre el biol a base de agua residual con un valor de $991.2 \mathrm{mg} / \mathrm{l}$ contra un valor de $621.6 \mathrm{mg} / \mathrm{L}$ del biol en base a agua de pozo. Esto se explica por la presencia de nitrógeno total en el agua residual en una concentración de $0.06 \%$ en comparación con la concentración de $0 \%$ presente en el agua de pozo.

Se observa que el biol a base de agua residual presenta mayor cantidad de nutrientes que el biol a base de agua de pozo. Estos valores son comparados con el biol comercial de Agricultura Casa Blanca (Ver Tabla 4).
En la Tabla 7 podemos apreciar los valores obtenidos para los análisis microbiológicos de los organismos patógenos que se analizaron: coliformes totales y coliformes fecales. Podemos observar que al inicio de la carga existe una presencia elevada de coliformes fecales y coliformes totales, la cual va disminuyendo conforme va dándose el proceso de biodigestión.

Tabla 7. Resultados de concentración de coliformes totales y coliformes fecales.

\begin{tabular}{ccccc}
\hline Etapa & $\begin{array}{c}\text { Coliformes totales } \\
(\mathrm{NMP} / 100 \mathrm{ml})\end{array}$ & $\begin{array}{c}\text { Coliformes fecales } \\
(\mathrm{NMP} / 100 \mathrm{ml})\end{array}$ \\
& $\begin{array}{c}\text { Tratamiento 1 Tratamiento 2 } \\
\text { Tratamiento } \\
1\end{array}$ & Tratamiento 2 \\
\hline Inicio & $49 \times 10^{4}$ & $22 \times 10^{4}$ & $22 \times 10$ & $<1.8$ \\
Final & $19.3 \times 10^{3}$ & $15.3 \times 10^{3}$ & 84 & $19,6 \times 10$ \\
\hline
\end{tabular}

Se observa para los coliformes totales una reducción de 
una unidad logarítmica lo que equivale a una reducción del $90 \%$ de organismos patógenos. Para los coliformes fecales se observa también la reducción en una unidad logarítmica. Sin embargo el valor inicial de coliformes fecales para el Tratamiento 2 es menor al valor final.

La reducción de una sola unidad logarítmica durante el proceso de biodigestión pudo haber sido afectada por la carga diaria. Al ir cargando diariamente los reactores, no solo se le incorpora materia orgánica sino también carga patógena, por lo tanto el tiempo de residencia y degradación no ha sido lo suficiente.

Para coliformes fecales se cumple los estándares establecidos para Calidad de Agua para riego establecidos en los Estándar de Calidad Ambiental para Agua (D.S. 002-2008 - MINAM) obteniéndose un valor muy por debajo de los $1000 \mathrm{NMP} / 100 \mathrm{ml}$. Para el caso de los coliformes totales el estándar establece un valor de 5000 $\mathrm{NMP} / 100 \mathrm{ml}$ que en este caso no se llega a cumplir.

\section{Conclusiones}

Las aguas grises y las aguas amarillas, como parte de las aguas residuales domésticas producidas por la población, son residuos líquidos que pueden ser reutilizados como sustitutos del agua de pozo para la alimentación de biodigestores para la producción de biogás y fertilizante líquido.

La calidad del biogás obtenido para los tratamientos aplicados se encuentra cerca del rango óptimo de calidad de biogás, es decir mayor al $50 \%$ de metano en su composición. Para el Tratamiento 1 se presenta un valor promedio máximo de $50.6 \%$ y para el Tratamiento 2 se presenta un valor promedio máximo de $48.6 \%$ de metano. Al realizar el análisis estadístico no se ha encontrado diferencia significativa entre estos dos resultados. La calidad del biogás producido utilizando aguas residuales (aguas amarillas y aguas grises) para la alimentación de los reactores (Tratamiento 1) presenta mayor porcentaje de metano dentro de su composición en comparación con el biogás producido utilizando agua de pozo para la alimentación (Tratamiento 2). Esto se ve directamente relacionado con la calidad del agua y las características del agua residual (agua gris y aguas amarillas).

El volumen de biogás producido utilizando aguas residuales como alimentación (Tratamiento 1) que en volumen acumulado equivale a 436.2 litros, fue mayor que el volumen producido utilizando agua de pozo (Tratamiento 2), que equivale a 357.4 litros de volumen acumulado, esto al igual que la calidad del biogás depende directamente de la calidad del agua residual utilizada, la cual presenta mayor contenido de sólidos volátiles dentro de su composición, lo que genera la mayor producción de biogás. Al realizarse el análisis estadístico respectivo no se ha encontrado diferencia significativa entre los resultados obtenidos.

Se ha determinado la influencia de la temperatura ambiental en la temperatura interna de los reactores, manteniéndose la temperatura interna en $6^{\circ} \mathrm{C}$ mayor que la temperatura ambiental.

Se ha determinado la reducción de organismos patógenos (coliformes totales y coliformes fecales) comparando la calidad inicial del sustrato ingresado al biodigestor con la calidad final de biol obtenido. Para los coliformes totales se ha logrado una reducción de una unidad logarítmica, es de decir del $90 \%$ de la carga patógena. Para el caso de los coliformes fecales ocurre lo mismo, se ha determinado una reducción de una unidad logarítmica.

El biol producido en los dos tratamientos presenta micronutrientes: Nitrógeno, Fósforo y Potasio en su composición. La calidad del biol para el tratamiento con aguas residuales presenta concentraciones mayores de macronutrientes que el biol obtenido con el tratamiento de agua de pozo. Esto se debe a la calidad del agua utilizada para la alimentación, es ahí donde se ve la influencia de la calidad de la misma sobre la calidad del producto final.

\section{Literatura citada}

Martí, J. 2008. Biodigestores Familiares. Guía de diseño y manual de instalación. Biodigestores de polietileno tubular de bajo costo para trópico, valle y altiplano. GTZ (Cooperación Técnica Alemana). Bolivia.

Decreto Supremo $\mathbf{N}^{\mathbf{0}}$ 002-2008-MINAM Estándares Nacionales de Calidad Ambiental para Agua. 